\section{The Need for a Prehospital DNR System Withholding CPR in the Prehospital Setting}

To the Editor:

The review of patient consent presented in your last issue by $\mathrm{R}$. Jack Ayres, JD, EMT-P, is an interesting synopsis of the topic from a legal viewpoint.

Although a disclaimer is provided, the discussion of involuntary consent skirts the issue of true emergent conditions in which the time delay for obtaining a court order may seriously jeopardize a patient's health. Many states have statutory laws which, when consent cannot be obtained from the patient or relative, permit physicians to initiate lifesaving treatment if mentally ill persons without a court order using a "reasonable person" standard, 1 and additional statutory provisions which allow the use of force in the prevention of suicide. ${ }^{2}$ Other states employ the common law standard of reasonableness to the same end. ${ }^{3}$ An example of such a patient would be an intoxicated, disoriented, and depressed individual who has ingested 100 tablets of a tricyclic antidepressant to commit suicide, and is refusing treatment and demanding discharge.

Of course, obtaining the voluntary, informed consent of adults with decision-making capacity, or a legally acceptable surrogate in those without capacity, always is preferable. However, when those options are unavailable in emergency situations, unless specifically limited by state statutory or common law, most legal and medical scholars would suggest provision of the treatment despite the patient's refusal. ${ }^{3-6}$

Frank W. Lavoie, MD, FACEP

Department of Emergency Medicine

University of Louisville School of

Medicine

Louisville, Kentucky, USA

\section{References}

1. Use of force by person with responsibility for care, discipline or safety of others. (Section 503.110) in: Legislative Research Commission. Kentucky Revised Statutes. Charlottesville: Michie Company, 1985 (vol 16A):50.

2. Prevention of a Suicide or crime (Section 503.100) in: Legislative Research Commission, Kentucky Revised Statutes Charlottesville: Michie Company, 1985 (Vol 16A):49.

3. Page JO: Legal aspects of behavioral and psychological emergencies. Top Emerg
Med $1983 ; 4(4): 66-70$.

4. Perry SW, Gilmore MM: The disruptive patient or visitor. JAMA 1981; 245:755-757.

5. Nelson LJ: The law, professional responsibility, and decisions to forego treatment. Quart Rev Bull 1986; 12(1):8-15.

6. Rund DA, Keller MD: To restrain or not to restrain. Emerg Med Serv 1986; $15(1): 24,46-49$.

Response:

I am pleased to respond to the insightful comments of Dr. LaVoie to my earlier article [in Prehospital and Disaster Medicine, V5,1, Jan-Mar 1990].

In this connection, Dr. LaVoie correctly points out that some states (including not only Kentucky but also florida and California) do in fact provide broad-ranging statutory authority for physicians to treat emergently ill patients, to prevent suicide, and to correct the consequences of child abuse. I certainly agree with Dr. LaVoie's implied assumption that such a statutory framework affords the greatest flexibility to the emergency physician, and subject to appropriate safeguards for abuse, in a number of cases represents a preferable alternative to obtaining court orders for such patients.

I certainly did not intend to "skirt the issue" regarding the time delay in obtaining such orders when necessary. In our own clinical practice at Parkland Memorial Hospital in Dallas, we have found that through previous arrangements with the presiding judge of the local district courts, we can obtain very rapid access to a district judge and very rapid determination as to whether or not such orders will be issued. In our practice, this system has proved extremely efficient in emergency circumstances. thus, I would encourage Dr. LaVoie and others who are interested in this subject to consider the development of legal liaison programs in which reputable counsel can be consulted and advance procedural systems established with appropriate courts to handle such emergencies.

Finally and perhaps most importantly, I agree wholeheartedly with Dr. LaVoie that in any medically or legally equivocal circumstances a prudent health care provider would be well advised to err on the side of preserving life.

I am most appreciative for Dr. LaVoie's thoughtful comments.

R. Jack Ayres, Jr., JD, EMT-P Attormey

\section{A Prospective Evaluation of Prehospital Patient Assessment by Direct In-Field Observation: Failure of ALS Personnel to Measure Vital Signs}

To the Editor:

The study, "A Prospective Evaluation of Prehospital Patient Assessment by Direct In-Field Observation: Failure of AIS Personnel to Measure Vital Signs," by Spaite et al, on face value is extremely disturbing.

The study implies that, as a standard of care, either a blood pressure and/or pulse was not taken in $37 \%$ of the patients $(26.5 \%$ of adults and $50.0 \%$ of children under 18 years of age). The authors concluded that:

"In a state-wide evaluation failure to measure vital signs occurred on a frequent basis. Out data indicated that a concerning lack of attention to the most basic details of patient assessment is common... It is of further concern that such a significant omission could be so widespread and not be detected by supervisory personnel... Furthermore, your results also suggest an apparent ineffectiveness in training and continuing education with respect to the importance of careful patient assessment."

An Editorial comment that follows the study (p. 333) states: "This is a frightening study..."

One must agree that if what one can validly conclude from the study is that, in a state-wide study, ALS responders (or EMTs at any level) arbitrarily omitted vital signs in greater than one-third of the patients assessed, it would, indeed, represent a "frightening" condemnation of the training, level of care, and quality control. However, upon careful reading, this reader can not draw such conclusions based upon the information provided, since too many questions remain unanswered.

Since the research technician making the observations was "chosen specifically as a non-medical professional," it remains unanswered whether this observer could identify pulse evaluation other than the specific palpating of a radial pulse and counting of the pulse rate using a wristwatch. If responders palpated radial, carotid, or femoral pulses, for presence/absence, quality, and estimated their rate, was this re- 